\title{
Climate Change 2013 The Physical Science Basis
}

\section{Working Group I Contribution to the Fifth Assessment Report of the Intergovernmental Panel on Climate Change}

\section{Edited by}

\author{
Thomas F. Stocker \\ Working Group I Co-Chair \\ University of Bern
}

Gian-Kasper Plattner

Melinda M.B. Tignor

Director of Science

Director of Operations

Alexander Nauels

Science Assistant

\begin{abstract}
Yu Xia
Science Officer
\end{abstract}

\author{
Dahe Qin \\ Working Group I Co-Chair \\ China Meteorological Administration \\ Simon K. Allen \\ Senior Science Officer \\ Judith Boschung \\ Administrative Assistant \\ Vincent Bex \\ IT Officer \\ Pauline M. Midgley \\ Head
}

Working Group I Technical Support Unit 
CAMBRIDGE UNIVERSITY PRESS

Cambridge, New York, Melbourne, Madrid, Cape Town, Singapore, São Paolo, Delhi, Mexico City

Cambridge University Press

32 Avenue of the Americas, New York, NY 10013-2473, USA

www.cambridge.org

Information on this title: www.cambridge.org/9781107661820

C) Intergovernmental Panel on Climate Change 2013

This publication is in copyright. Subject to statutory exception and to the provisions of relevant collective licensing agreements, no reproduction of any part may take place without the written permission of Cambridge University Press.

First published 2013

Printed in the United States of America

A catalog record for this publication is available from the British Library.

ISBN 978-1-107-05799-1 hardback

ISBN 978-1-107-66182-0 paperback

Cambridge University Press has no responsibility for the persistence or accuracy of URLs for external or third-party Internet Web sites referred to in this publication and does not guarantee that any content on such Web sites is, or will remain, accurate or appropriate.

Please use the following reference to the whole report:

IPCC, 2013: Climate Change 2013: The Physical Science Basis. Contribution of Working Group I to the Fifth Assessment Report of the Intergovernmental Panel on Climate Change [Stocker, T.F., D. Qin, G.-K. Plattner, M. Tignor, S.K. Allen, J. Boschung, A. Nauels, Y. Xia, V. Bex and P.M. Midgley (eds.)]. Cambridge University Press, Cambridge, United Kingdom and New York, NY, USA, 1535 pp.

Cover photo:

Folgefonna glacier on the high plateaus of Sørfjorden, Norway $\left(60^{\circ} 03^{\prime} \mathrm{N}-6^{\circ} 20^{\prime} \mathrm{E}\right)$ ) (C) Yann Arthus-Bertrand / Altitude. 
Foreword, Preface and Dedication 



\section{Foreword}

"Climate Change 2013: The Physical Science Basis" presents clear and robust conclusions in a global assessment of climate change sciencenot the least of which is that the science now shows with 95 percent certainty that human activity is the dominant cause of observed warming since the mid-20th century. The report confirms that warming in the climate system is unequivocal, with many of the observed changes unprecedented over decades to millennia: warming of the atmosphere and the ocean, diminishing snow and ice, rising sea levels and increasing concentrations of greenhouse gases. Each of the last three decades has been successively warmer at the Earth's surface than any preceding decade since 1850 .

These and other findings confirm and enhance our scientific understanding of the climate system and the role of greenhouse gas emissions; as such, the report demands the urgent attention of both policymakers and the general public.

As an intergovernmental body jointly established in 1988 by the World Meteorological Organization (WMO) and the United Nations Environment Programme (UNEP), the Intergovernmental Panel on Climate Change (IPCC) has provided policymakers with the most authoritative and objective scientific and technical assessments. Beginning in 1990, this series of IPCC Assessment Reports, Special Reports, Technical Papers, Methodology Reports and other products have become standard works of reference.

This Working Group I contribution to the IPCC's Fifth Assessment Report contains important new scientific knowledge that can be used to produce climate information and services for assisting society to act to address the challenges of climate change. The timing is particularly significant, as this information provides a new impetus, through clear and indisputable physical science, to those negotiators responsible for concluding a new agreement under the United Nations Framework Convention on Climate Change in 2015.

Climate change is a long-term challenge, but one that requires urgent action given the pace and the scale by which greenhouse gases are accumulating in the atmosphere and the risks of a more than 2 degree Celsius temperature rise. Today we need to focus on the fundamentals and on the actions otherwise the risks we run will get higher with every year.

This Working Group I assessment was made possible thanks to the commitment and dedication of many hundreds of experts worldwide, representing a wide range of disciplines. WMO and UNEP are proud that so many of the experts belong to their communities and networks. We express our deep gratitude to all authors, review editors and expert reviewers for devoting their knowledge, expertise and time. We would like to thank the staff of the Working Group I Technical Support Unit and the IPCC Secretariat for their dedication.
We are also grateful to the governments that supported their scientists' participation in developing this report and that contributed to the IPCC Trust Fund to provide for the essential participation of experts from developing countries and countries with economies in transition. We would like to express our appreciation to the government of Italy for hosting the scoping meeting for the IPCC's Fifth Assessment Report, to the governments of China, France, Morocco and Australia for hosting drafting sessions of the Working Group I contribution and to the government of Sweden for hosting the Twelfth Session of Working Group I in Stockholm for approval of the Working Group I Report. The generous financial support by the government of Switzerland, and the logistical support by the University of Bern (Switzerland), enabled the smooth operation of the Working Group I Technical Support Unit. This is gratefully acknowledged.

We would particularly like to thank Dr. Rajendra Pachauri, Chairman of the IPCC, for his direction and guidance of the IPCC and we express our deep gratitude to Professor Qin Dahe and Professor Thomas Stocker, the Co-Chairs of Working Group I for their tireless leadership throughout the development and production of this report.

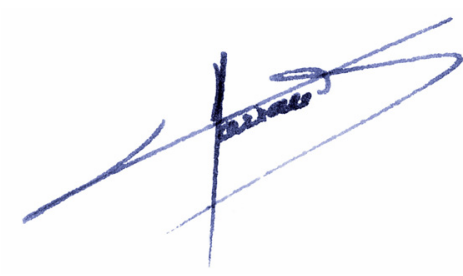

\section{Jarraud}

Secretary-General

World Meteorological Organization

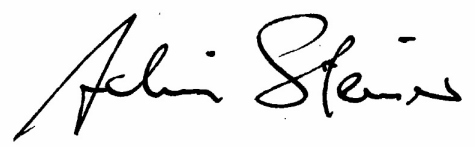

\section{A. Steiner}

Executive Director

United Nations Environment Programme 



\section{Preface}

The Working Group I contribution to the Fifth Assessment Report of the Intergovernmental Panel on Climate Change (IPCC) provides a comprehensive assessment of the physical science basis of climate change. It builds upon the Working Group I contribution to the IPCC's Fourth Assessment Report in 2007 and incorporates subsequent new findings from the Special Report on Managing the Risks of Extreme Events and Disasters to Advance Climate Change Adaptation, as well as from research published in the extensive scientific and technical literature. The assessment considers new evidence of past, present and projected future climate change based on many independent scientific analyses from observations of the climate system, paleoclimate archives, theoretical studies of climate processes and simulations using climate models.

\section{Scope of the Report}

During the process of scoping and approving the outline of its Fifth Assessment Report, the IPCC focussed on those aspects of the current understanding of the science of climate change that were judged to be most relevant to policymakers.

In this report, Working Group I has extended coverage of future climate change compared to earlier reports by assessing near-term projections and predictability as well as long-term projections and irreversibility in two separate chapters. Following the decisions made by the Panel during the scoping and outline approval, a set of new scenarios, the Representative Concentration Pathways, are used across all three Working Groups for projections of climate change over the 21st century. The coverage of regional information in the Working Group I report is expanded by specifically assessing climate phenomena such as monsoon systems and their relevance to future climate change in the regions.

The Working Group I Report is an assessment, not a review or a text book of climate science, and is based on the published scientific and technical literature available up to 15 March 2013. Underlying all aspects of the report is a strong commitment to assessing the science comprehensively, without bias and in a way that is relevant to policy but not policy prescriptive.

\section{Structure of the Report}

This report consists of a short Summary for Policymakers, a longer Technical Summary and fourteen thematic chapters plus annexes. An innovation in this Working Group I assessment is the Atlas of Global and Regional Climate Projections (Annex I) containing time series and maps of temperature and precipitation projections for 35 regions of the world, which enhances accessibility for stakeholders and users.
The Summary for Policymakers and Technical Summary of this report follow a parallel structure and each includes cross-references to the chapter and section where the material being summarised can be found in the underlying report. In this way, these summary components of the report provide a road-map to the contents of the entire report and a traceable account of every major finding.

In order to facilitate the accessibility of the findings of the Working Group I assessment for a wide readership and to enhance their usability for stakeholders, each section of the Summary for Policymakers has a highlighted headline statement. Taken together, these 19 headline statements provide an overarching summary in simple and quotable language that is supported by the scientists and approved by the member governments of the IPCC. Another innovative feature of this report is the presentation of Thematic Focus Elements in the Technical Summary that provide end to end assessments of important crosscutting issues in the physical science basis of climate change.

Introduction (Chapter 1): This chapter provides information on the progress in climate change science since the First Assessment Report of the IPCC in 1990 and gives an overview of key concepts, indicators of climate change, the treatment of uncertainties and advances in measurement and modelling capabilities. This includes a description of the future scenarios and in particular the Representative Concentration Pathway scenarios used across all Working Groups for the IPCC's Fifth Assessment Report.

Observations and Paleoclimate Information (Chapters 2, 3, 4, 5): These chapters assess information from all climate system components on climate variability and change as obtained from instrumental records and climate archives. They cover all relevant aspects of the atmosphere including the stratosphere, the land surface, the oceans and the cryosphere. Timescales from days to decades (Chapters 2, 3 and 4) and from centuries to many millennia (Chapter 5 ) are considered.

Process Understanding (Chapters 6 and 7): These chapters cover all relevant aspects from observations and process understanding to projections from global to regional scales for two key topics. Chapter 6 covers the carbon cycle and its interactions with other biogeochemical cycles, in particular the nitrogen cycle, as well as feedbacks on the climate system. For the first time, there is a chapter dedicated to the assessment of the physical science basis of clouds and aerosols, their interactions and chemistry, and the role of water vapour, as well as their role in feedbacks on the climate system (Chapter 7).

From Forcing to Attribution of Climate Change (Chapters 8, 9, 10): All the information on the different drivers (natural and anthropogenic) of climate change is collected, expressed in terms of Radiative Forcing and assessed in Chapter 8. In Chapter 9, the hierarchy of climate models used in simulating past and present climate change is assessed and evaluated against observations and paleoclimate reconstructions. 
Information regarding detection of changes on global to regional scales and their attribution to the increase in anthropogenic greenhouse gases is assessed in Chapter 10.

Future Climate Change, Predictability and Irreversibility (Chapters 11 and 12): These chapters assess projections of future climate change derived from climate models on time scales from decades to centuries at both global and regional scales, including mean changes, variability and extremes. Fundamental questions related to the predictability of climate as well as long term climate change, climate change commitments and inertia in the climate system are addressed. Knowledge on irreversible changes and surprises in the climate system is also assessed.

Integration (Chapters 13 and 14): These chapters synthesise all relevant information for two key topics of this assessment: sea level change (Chapter 13) and climate phenomena across the regions (Chapter 14). Chapter 13 presents an end to end assessment of information on sea level change based on paleoclimate reconstructions, observations and process understanding, and provides projections from global to regional scales. Chapter 14 assesses the most important modes of variability in the climate system, such as El Niño-Southern Oscillation, monsoon and many others, as well as extreme events. Furthermore, this chapter deals with interconnections between the climate phenomena, their regional expressions and their relevance for future regional climate change.

Maps assessed in Chapter 14, together with Chapters 11 and 12, form the basis of the Atlas of Global and Regional Climate Projections in Annex I, which is also available in digital format. Radiative forcings and estimates of future atmospheric concentrations from Chapters 7, 8, 11 and 12 form the basis of the Climate System Scenario Tables presented in Annex II. All material including high-resolution versions of the figures, underlying data and Supplementary Material to the chapters is also available online: www.climatechange2013.org.

The scientific community and the climate modelling centres around the world brought together their activities in the Coordinated Modelling Intercomparison Project Phase 5 (CMIP5), providing the basis for most of the assessment of future climate change in this report. Their efforts enable Working Group I to deliver comprehensive scientific information for the policymakers and the users of this report, as well as for the specific assessments of impacts carried out by IPCC Working Group II, and of costs and mitigation strategies, carried out by IPCC Working Group III.

Following the successful introduction in the previous Working Group I assessment in 2007, all chapters contain Frequently Asked Questions. In these the authors provide scientific answers to a range of general questions in a form that will be accessible to a broad readership and serves as a resource for teaching purposes. Finally, the report is accompanied by extensive Supplementary Material which is made available in the online versions of the report to provide an additional level of detail, such as description of datasets, models, or methodologies used in chapter analyses, as well as material supporting the figures in the Summary for Policymakers.

\section{The Process}

This Working Group I Assessment Report represents the combined efforts of hundreds of leading experts in the field of climate science and has been prepared in accordance with rules and procedures established by the IPCC. A scoping meeting for the Fifth Assessment Report was held in July 2009 and the outlines for the contributions of the three Working Groups were approved at the 31st Session of the Panel in November 2009. Governments and IPCC observer organisations nominated experts for the author team. The team of 209 Coordinating Lead Authors and Lead Authors plus 50 Review Editors selected by the Working Group I Bureau was accepted at the 41st Session of the IPCC Bureau in May 2010. In addition, more than 600 Contributing Authors provided draft text and information to the author teams at their request. Drafts prepared by the authors were subject to two rounds of formal review and revision followed by a final round of government comments on the Summary for Policymakers. A total of 54,677 written review comments were submitted by 1089 individual expert reviewers and 38 governments. The Review Editors for each chapter monitored the review process to ensure that all substantive review comments received appropriate consideration. The Summary for Policymakers was approved line-by-line and the underlying chapters were then accepted at the 12th Session of IPCC Working Group I from 23-27 September 2007.

\section{Acknowledgements}

We are very grateful for the expertise, hard work, commitment to excellence and integrity shown throughout by the Coordinating Lead Authors and Lead Authors with important help by the many Contributing Authors. The Review Editors have played a critical role in assisting the author teams and ensuring the integrity of the review process. We express our sincere appreciation to all the expert and government reviewers. We would also like to thank the members of the Bureau of Working Group I: Jean Jouzel, Abdalah Mokssit, Fatemeh Rahimizadeh, Fredolin Tangang, David Wratt and Francis Zwiers, for their thoughtful advice and support throughout the preparation of the report.

We gratefully acknowledge the long-term efforts of the scientific community, organized and facilitated through the World Climate Research Programme, in particular CMIP5. In this effort by climate modelling centres around the world, more than 2 million gigabytes of numerical data have been produced, which were archived and distributed under the stewardship of the Program for Climate Model Diagnosis and Intercomparison. This represents an unprecedented concerted effort by the scientific community and their funding institutions. 
Preface

Our sincere thanks go to the hosts and organizers of the four Working Group I Lead Author Meetings and the 12th Session of Working Group I. We gratefully acknowledge the support from the host countries: China, France, Morocco, Australia and Sweden. The support for their scientists provided by many governments as well as through the IPCC Trust Fund is much appreciated. The efficient operation of the Working Group I Technical Support Unit was made possible by the generous financial support provided by the government of Switzerland and logistical support from the University of Bern (Switzerland).

We would also like to thank Renate Christ, Secretary of the IPCC, and the staff of the IPCC Secretariat: Gaetano Leone, Jonathan Lynn, Mary Jean Burr, Sophie Schlingemann, Judith Eva, Jesbin Baidya, Werani Zabula, Joelle Fernandez, Annie Curtin, Laura Biagioni and Amy Smith. Thanks are due to Francis Hayes who served as the conference officer for the Working Group I Approval Session.

Nachanm

Rajendra K. Pachauri IPCC Chair
Q in Dale

Quin Dane

IPCC WGI Co-Chair
Finally our particular appreciation goes to the Working Group I Technical Support Unit: Gian-Kasper Platter, Melinda Tignor, Simon Allen, Judith Boschung, Alexander Navels, Yo Kia, Vincent Rex and Pauline Midgley for their professionalism, creativity and dedication. Their tireless efforts to coordinate the Working Group I Report ensured a final product of high quality. They were assisted in this by Adrien Michel and Flavio Lehner with further support from Chou Botao and Sun Ping. In addition, the following contributions are gratefully acknowledged: David Hanford (editorial assistance with the Frequently Asked Quesions), UNEP/GRID-Geneva and University of Geneva (graphics assisrance with the Frequently Asked Questions), Theresa Kornak (copyedit), Marilyn Anderson (index) and Michael Shibao (design and layout).

胥

Roman foch

Thomas F. Stoker

IPCC WGI Co-Chair

ix 



\section{Dedication}

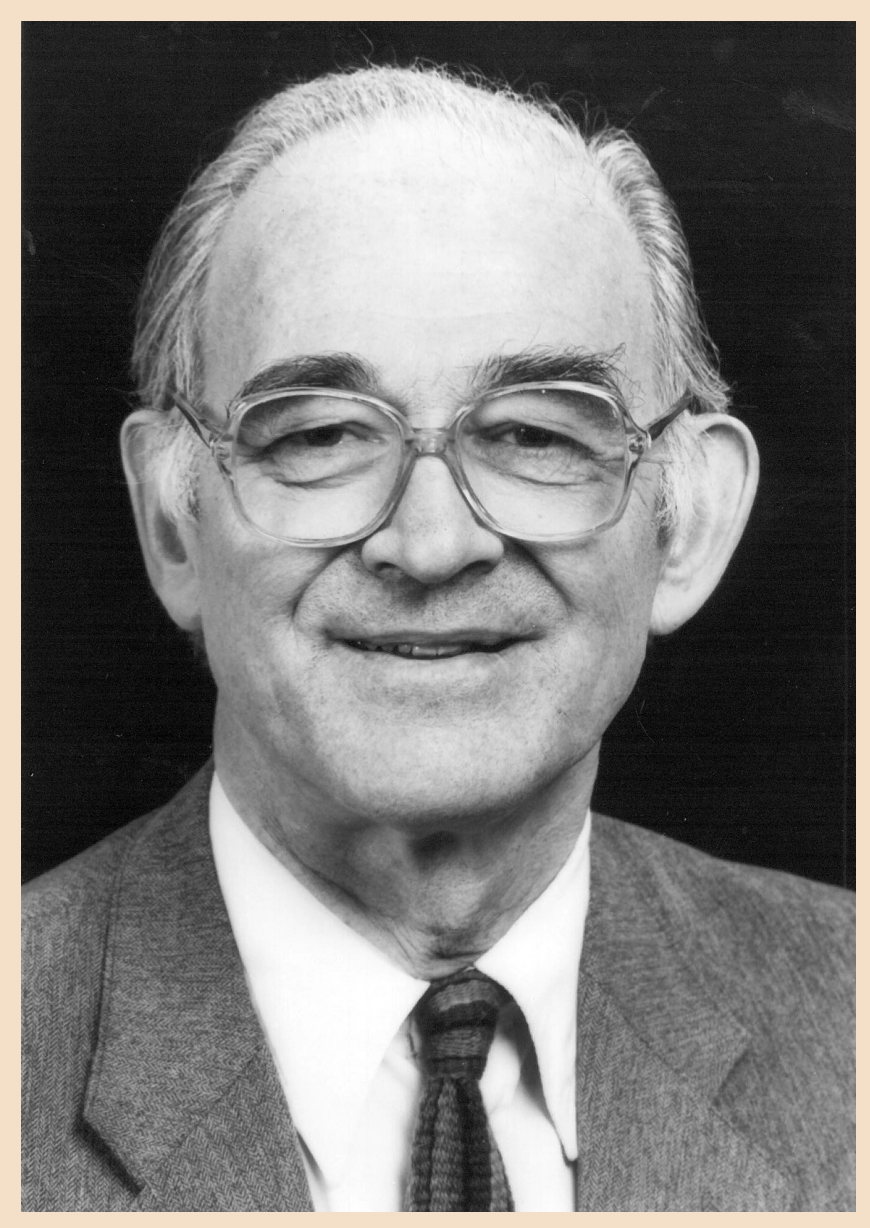

Bert Bolin

(15 May 1925 - 30 December 2007)

The Working Group I contribution to the Fifth Assessment Report of the Intergovernmental Panel on Climate Change (IPCC) Climate Change 2013: The Physical Science Basis is dedicated to the memory of Bert Bolin, the first Chair of the IPCC.

As an accomplished scientist who published on both atmospheric dynamics and the carbon cycle, including processes in the atmosphere, oceans and biosphere, Bert Bolin realised the complexity of the climate system and its sensitivity to anthropogenic perturbation. He made a fundamental contribution to the organisation of international cooperation in climate research, being involved in the establishment of a number of global programmes.

Bert Bolin played a key role in the creation of the IPCC and its assessments, which are carried out in a unique and formalized process in order to provide a robust scientific basis for informed decisions regarding one of the greatest challenges of our time. His vision and leadership of the Panel as the founding Chair from 1988 to 1997 laid the basis for subsequent assessments including this one and are remembered with deep appreciation. 



\section{Contents}

Front Matter

Foreword

Preface

Dedication

Summary for Policymakers

Technical Summary

\section{TS}

Chapter 1 Introduction

Chapter 2 Observations : Atmosphere and Surface

Chapter 3 Observations: Ocean

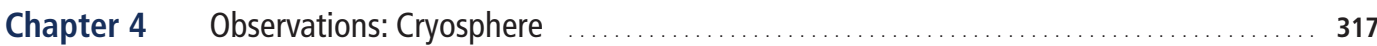

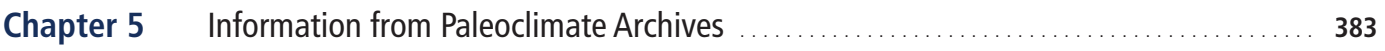

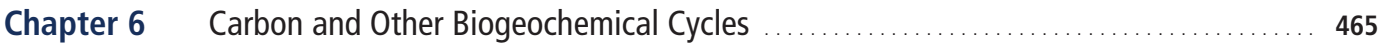

Chapter $7 \quad$ Clouds and Aerosols ........................................................ 571

Chapter $8 \quad$ Anthropogenic and Natural Radiative Forcing …...............................6. 659

Chapter 9 Evaluation of Climate Models ........................................... 741

Chapter 10 Detection and Attribution of Climate Change: from Global to Regional ............. 867

Chapter 11 Near-term Climate Change: Projections and Predictability …................. 953

Chapter 12 Long-term Climate Change: Projections, Commitments and Irreversibility .......... 1029

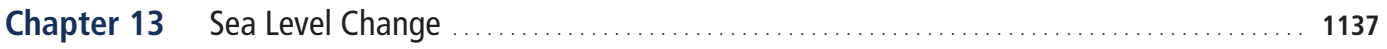

Chapter 14 Climate Phenomena and their Relevance for Future Regional Climate Change . .... 1217

Annexes

Annex I Atlas of Global and Regional Climate Projections

Annex II Climate System Scenario Tables _............................................ 1395

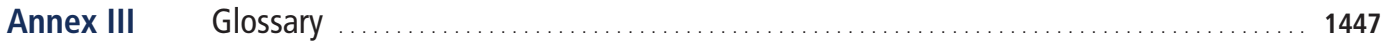

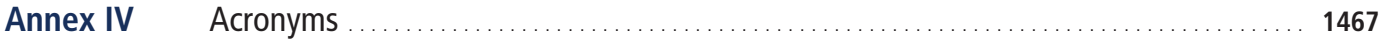

Annex V Contributors to the IPCC WGI Fifth Assessment Report ........................ 1477

Annex VI Expert Reviewers of the IPCC WGI Fifth Assessment Report . . . . . . . . . . . . . . . 1497

Index 
